\title{
Adult Education - Facing the Future
}

Judy Mortrude, World Education, Inc.

Over the past year, the field of adult basic education has mounted a strong response to COVID-19's disruption of classes and educational practices. As we begin to think about the longterm consequences of this disruption, it might be useful to consider the ways that these changes and innovations could be built upon. In the first place, some of the innovations developed by programs and institutions address important structural problems in adult education programming. Additionally, the pandemic will increase the need for adult education as so many more people have experienced "interrupted or deficient education" and some subset of those will remain disconnected from K12. In order to understand these issues, I first outline some of the key policy issues that have become clear over the past year and then make a plea to adult educators not to return to business as usual.

\section{Initial Responses: Emergency Remote Teaching and Learning}

As COVID-19 necessitated community-wide closures beginning in March 2020, adult education joined the international natural experiment in emergency remote teaching and learning. Like many other educators, adult educators tackled challenges and developed new skills, strategies, and program models with energy and commitment. Some of these responses were documented by a collaborative of adult education researchers and practitioners who conducted interviews with practitioners, administrators, and state staff just weeks into the school shut down orders, producing a snapshot of the pandemic's immediate impact on adult education (Belzer et al., 2020). Vanek and Mortrude (2020) followed up the initial studies by convening multiple researchers with the task of looking across their findings to identify cross-cutting themes. Some common issues that emerged include:

- the importance of leadership providing timely communication and supportive policy and practices;

- the need for and practitioners' intense engagement in high quality, multi-layered professional development;

- strategies for supporting access to devices, connectivity, and non-educational resources for learners and instructors;

- the resilience and creative problem solving that emerged among practitioners to meet learners' immediate needs; and,

- recognition that although much was lost without daily face to face interactions, much had been gained in terms of learning to support students across time and distance.

As 2020 wore on, it became clear that while many adult educators had adjusted to remote teaching, there was inadequate funding for the kind of programming shifts necessary to sustain 
their work and ensure high quality instructional and programmatic delivery. For example, the Federal CARES Act funding for education did not specifically allocate resources for adult education. Instead, the decision about using funds for adult education was left to the states, setting off advocacy campaigns to convince governors to provide the needed funds for adult education, especially for expanding adult access to devices and connectivity.

Local adult education programs - like their K12 and post-secondary colleagues - often whiplashed between opening and closing restrictions. In addition to trying to meet the needs of their students, they had to comply with the various state and federal regulations and procedures. Testing companies developed remote proctoring processes so that programs could restart assessment and accountability procedures, but barriers related to training, cost, and equipment remained for many programs and learners. Stories like that of a young woman 5 hours into an online test in her bedroom closet who was interrupted by her toddler needing attention and then told her test (and time) were invalid made educators wonder what this system they had created was designed to do.

At the federal level, there were attempts to provide needed guidance and support and extend funding. Specifically, the U.S. Department of Education allowed states to apply for a waiver to extend the deadline on expending Adult Education and Family Literacy Act (AELFA) funds, allowing programs that temporarily closed to use grant dollars longer into the future. The Department also released a series of FAQs pertaining to policy (U.S. Department of Education, 2020). As 2020 drew to a close, state adult education directors sought to capture all these challenges in yearend narrative reports to the agency responsible for monitoring federal adult education funds.
We look forward to the U.S. Department of Education's release of a public facing report on adult education's COVID-19 response distilled from these narratives.

\section{Moving Forward: Changed Work and Changed Education}

In 2021, uncertainty prevails, and a sense of stasis grips the adult education field that seems both ready to retreat to the status quo as soon as possible and, at the same time, open to reinventing itself whole cloth. What have we learned? How can we prepare for the future? While only time will provide answers, there are lessons from the past and signals from the present to guide us.

The pandemic accelerated and exacerbated economic trends that have been developing for decades. The first such trend describes the changing job market and the need for training and retraining. A second, related trend, is the continued replacement of workers with automation. Prior to the pandemic, discussions about the future of work often mentioned increasing automation and the elimination of many jobs, particularly affecting workers with less education and income who are disproportionately Black, Indigenous, and people of color. COVID-19 has accelerated this phenomenon as workplaces have invested in automation as a means of continuing operation with less human intervention. Early data suggest this will outlast the pandemic (Toland \& Huddart, n.d.). Thirdly, recent data reveals that declining employment growth because of COVID-19 is almost exclusively in jobs that require a high school diploma or no diploma at all, meaning adults with the least educational attainment are hit hardest now and into the future (Kolko, 2021).

Because of all these economic changes, it is 
essential that adult education play a critical role in building not only occupationally specific skills through integrated education and training but also what are often called personal and workplace success skills (National College Transition Network, n.d.). Concentration on these types of skills - employability skills, academic, and career skills - is not new for adult education, but it is time to update them with thinking afresh about the types of human skills needed in our accelerating artificial intelligence and machine learning economies (Weise, 2021). COVID-19 has taught us all that we will continually need to adapt to changing work environments and hone our abilities to communicate and collaborate. We need an adult education system that values this skill building as much as reading level gains.

Finally, adult education has been consistently concerned that its learners and practitioners do not possess the digital skills needed for now and the future. The problems of providing remote education during the pandemic underscored this issue. If the field of adult education is to play a vital role in the education ecosystem into the future, we will need an increased focus on digital skills and digital resilience in life, family, and at work along with critically important humancentered skills. In order to achieve this goal, adult education needs to actively create its space in the spectrum of education.

\section{Policy Initiatives for Building Digital Skills and Human Skills}

The pandemic revealed great disparities in digital access. It has clearly demonstrated that lack of access to high-speed internet connections, internet-enabled devices, and digital skills training disproportionately affect low-income adults and members of Black, Indigenous, and people of color communities everywhere. For instance, while overall 7.4\% of Michiganders have only smartphone access to a computing device, the rate in Wayne County, where Detroit is located, is $10.7 \%$. Further, fully $70 \%$ of Detroit's schoolage children do not have internet access at home. Additionally, deep mapping by the University of Michigan reveals the pattern of Black neighborhoods as dramatically under-resourced in access and devices (Urban Collaboratory at the University of Michigan, 2019).

These disparities reveal adult education's critical role in addressing digital access and digital skill building within the context of racial equity. The first purpose of adult education according to the Workforce Innovation and Opportunity Act (WIOA) is to serve individuals with barriers to employment, which means people confronting multiple barriers to educational and economic opportunities. These individuals are disproportionately represented in Black, Indigenous, people of color communities, and so are disproportionately represented in adult education programs. Adult education is the title in WIOA under which digital literacy is defined, included as a component of workforce preparation, and designated an allowable activity within WIOA Title II adult education funds. However, increasing digital literacy is not currently fully recognized or rewarded by federal and state funders as a key activity in adult education classrooms.

Digital literacy is essential for our ever more digitized world. While WIOA Title II funds allow for expenditures on digital literacy, there has been no way within the WIOA Title II National Reporting System to document digital literacy skill gain. This means that hours of time spent teaching valuable skills for learning, working, and living online have been essentially worth nothing in the WIOA Title II federal accountability system. Adult education needs to be fully prepared 
to provide digital skill building and 'count' the work in our accountability system. A recent open comment period on adult education's National Reporting System included powerful calls for rethinking distance education reporting and WIOA performance accountability (Coalition on Adult Basic Education, n.d.) and important changes are underway to document these skill gains. With WIOA reauthorization talks beginning, this targeted advocacy needs to grow.

The pandemic has highlighted not only the need for a federal role in expanding broadband access to all regions of the country, but also the need for investment in educational technology. Adult educators now clearly see the value in always having a digital classroom as a complement to face-to-face work. An online presence allows them to mitigate transportation, childcare, and work schedule barriers; to use a blended learning strategy through a flipped classroom approach; and to both prepare adult learners to support children's learning and their own entry to postsecondary education where digital skills are required.

Beyond WIOA, there are powerful ways for adult education to collaborate widely as a way to promote digital equity, digital inclusion, and digital resilience. One example of this is Digital US which is a growing cross-sector coalition, led by World Education's EdTech Center, which includes educators, advocates, employers, and workforce professionals putting their efforts together to meet the digital equity imperative. The Digital Navigator model "addresses multiple layers of digital inclusion. Its goal is to ensure residents receive on-demand tech support and relevant information to secure connectivity and devices, as well as access to foundational digital literacy skills, learning and job training" (Digital US, n.d.). In this model, communities develop their own cadre of Navigators, including adult education providers, who can provide just-in-time, individualized support via a variety of communication methods that best serve the adult learner.

\section{Adult Education as Integral in Community-Wide Education Solutions}

Over the past year, it has become clearer than ever that adult education needs to be an integral part of community-wide educational solutions. The Biden FY22 budget commits to large-scale investments in education at the K12 and postsecondary levels, and calls out adult education within the context of community schools designed to meet holistic family needs (Young, 2021). This is critical work for adult education, but yet again, the federal adult education reporting and performance accountability system fails to capture adult education's role in a community-wide education strategy. Adult education leaders across the country need to center adult basic education's critical place in a community's education services continuum, and it is important to look at not only what happens in the classroom but also at the system itself.

One promising approach was developed in New Hampshire during COVID-19. The education system invested in a common learning management system platform across K12, adult education, and postsecondary education, thus weaving adult education into the educational fabric of the community. In this way, New Hampshire was able to show the value of adult education within the whole family and to the whole community. Another illustration of leveraging adult education to support a communitywide education strategy comes from Northstar Digital Literacy. Started by adult educators in Minnesota and now used nationally and even internationally, Northstar recently developed standards, curriculum, and an assessment for Supporting 


\section{K-12 Distance Learning with CARES Act} funding (Northstar Digital Literacy, n.d.). These solutions demonstrate the importance of having adult education at the table when developing a communitywide education strategy.

In the future, adult educators need to be included in a broader discussion about educational investment. For example, when the Biden administration makes an equity investment in ESSA Title I schools for low-income children, it should also provide resources to build an equitable educational opportunity for the adult parents and family members of those children who are experiencing barriers to economic mobility. The National Coalition for Literacy (Kennedy, 2021) requested that the new administration:

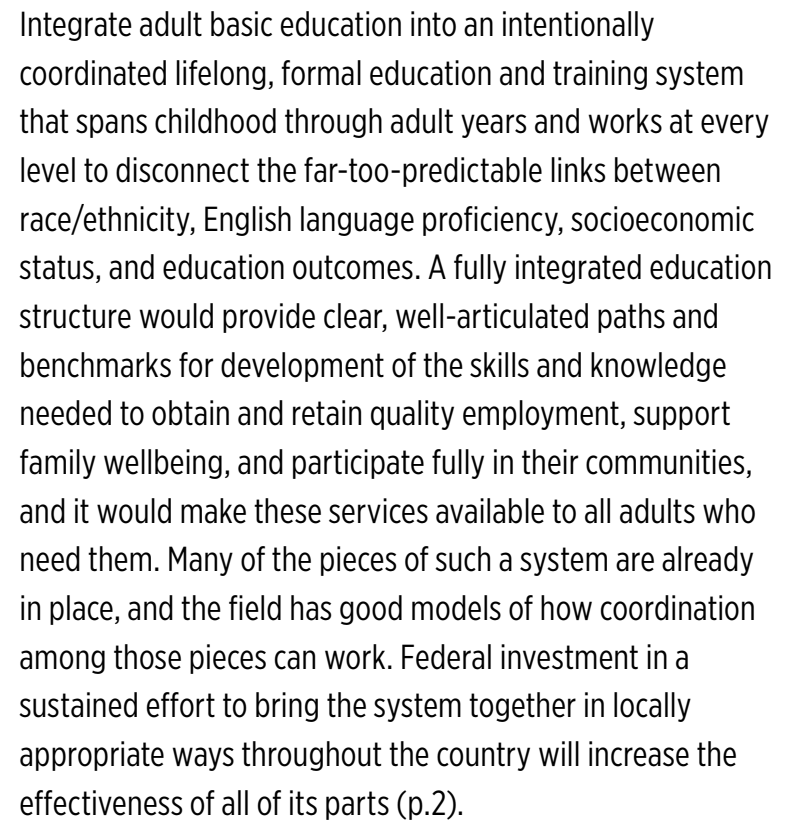

The pandemic has clearly highlighted the interconnected nature of our education systems. Without parents or caregivers with digital access and skills, children could not fully participate in remote learning. (Of course, this is true of nonremote learning as well.) Children whose parents or caregivers need digital access and skills are at a disadvantage. Adult education needs to be an integral part of designing community wide education strategies.

\section{Future Facing Adult Education}

As we look to a future free from COVID-19, I urge adult educators to resist inertia and the pull to go back to the way it was. I am hopeful that adult educators will be bold in reimagining their future program design. We need to be ready for WIOA reauthorization hearings in the spring of 2021 and demand the performance accountability system we need to show adult education's true value within the full spectrum of education. We also need to honor adult education's ability to meet community members where they are and to support individualized learning. Finally, we should articulate the value of adult education not only for the individual but for the community.

By building on what we have learned during the pandemic, we can focus more resources on building practitioners' and learners' digital and uniquely human skills which can, in turn, support resilience within the family, at work, and in local communities. By joining forces with other education stakeholders in our communities, adult education can be a partner in communitywide education solutions. Among the many consequences of COVID-19 may be yet more individuals with interrupted learning who will need adult education services. Let us prepare to meet the future. 


\section{References}

Belzer, A., Leon, T., Patterson, M., Rhodes, C., SalasIsnardi, F., Vanek, J., Webb, C., Wilson-Toro, B. (2020). COVID-19 rapid response report from the field. ProLiteracy. http://www.proliteracy.org/Resources/ Research

Coalition on Adult Basic Education. Supporting enhancements to the NRS. https://coabe.org/nrscomments/

Digital US. (n.d.). Digital navigators. https://digitalus.org/ digital-navigators/

Kennedy, D. (2021, January 6). Access and inclusion: Adult education and literacy priorities for 2021 and beyond. National Coalition for Literacy. https://national-coalitionliteracy.org/2021/01/access-and-inclusion-adulteducation-and-literacy-priorities-for-2021-and-beyond/.

Kolko, J. (2021, February 22). The jobs the pandemic may devastate. New York Times. https://www.nytimes. com/2021/02/22/upshot/jobs-future-pandemic-. $\mathrm{html}$ ?referringSource $=$ articleShare

Northstar Digital Literacy. (n.d.). https://www. digitalliteracyassessment.org/

National College Transition Network. (n.d.). https://www.collegetransition.org/college-careerreadiness/featured-projects/personal-success-skills/. 